\title{
DIMENSÕES ASSOCIADAS A SÍNDROME DE BURNOUT EM PROFESSORES: UMA ANÁLISE CRÍTICA
}

\section{DIMENSIONS ASSOCIATED WITH BURNOUT SYNDROME IN TEACHERS: A CRITICAL ANALYSIS}

\begin{abstract}
Kéllen Campos Castro Moreira1 ${ }^{1}$, Nilva Rosa da Silva Magalhães², Mariselena Martins Silva de Araujo ${ }^{3}$

${ }^{1}$ Universidade Federal de Uberlândia, Uberlândia, MG, Brasil.

${ }^{2}$ Centro Universitário do Triângulo, Uberlândia, MG, Brasil

${ }^{3}$ Escola Municipal Professor Otávio Batista Coelho Filho, Uberlândia, MG, Brasil.

*kellen_camposcastro@yahoo.com.br
\end{abstract}

\section{RESUMO}

A Síndrome de Burnout pode ser definida como um esgotamento, cujo profissionais da educação estão entre a categoria mais afetada. Este artigo objetivou analisar as dimensões associadas à Síndrome de Burnout em docentes, de uma escola pública, em um município localizado em Minas Gerais. Utilizou a abordagem quantitativa, do tipo pesquisa de campo. A coleta de dados ocorreu por meio da aplicação de questionários, que foram analisados pelas dimensões: Exaustão Emocional, Despersonalização e Realização Pessoal no Trabalho. Dentre os resultados tem-se como itens mais assinalados conforme as dimensões: Sinto que através do meu trabalho influencio positivamente a vida dos outros, Sinto-me esgotado no final de um dia de trabalho, Tenho me tornado mais insensível com as pessoas. Os professores se comprometem fortemente com a profissão, evidenciado na dimensão Realização Pessoal no Trabalho. Porém, se deparam com condições nem sempre favoráveis para o trabalho resultando em Exaustão Emocional. Somado ao convívio e envolvimento diário com a comunidade acabam por exacerbar o desgaste e desenvolver um mecanismo de proteção, a Despersonalização. Sabe-se que a Síndrome de Burnout pode gerar além de perda de qualidade de vida dos professores, em implicações pedagógicas. Reconhece-se as limitações deste estudo e sugerese mais pesquisas e esforços para a melhoria das condições de trabalho (estrutura física, salário, carga horária) e da saúde mental, com espaços para compartilhar angústias, desafios e conquistas dos professores na escola.

Palavras-chave: "Maslach Burnout Inventory". Professores. Síndrome de burnout.

\section{ABSTRACT}

Burnout Syndrome can be defined as exhaustion, whose education professionals are among the most affected category. This article aimed to analyze the dimensions associated with Burnout Syndrome in teachers, from a public school, in a city located in Minas Gerais. Data collection occurred through the application of a questionnaire, which were analyzed by the dimensions: Emotional Exhaustion, Depersonalization and Personal Achievement at Work. Among the 
results, the most marked items are according to the dimensions: I feel that through my work I positively influence the lives of others, I feel exhausted at the end of a working day, I have become more insensitive with people. Teachers are strongly committed to the profession, as evidenced in the Personal Achievement at Work dimension. However, they are faced with conditions that are not always favorable for work resulting in Emotional Exhaustion. In addition to daily coexistence and involvement with the community, they end up exacerbating wear and tear and developing a protection mechanism, Depersonalization. It is known that the Burnout Syndrome can generate, in addition to loss of quality of life of teachers, in pedagogical implications. The limitations of this study are recognized and more research and efforts are suggested to improve working conditions (physical structure, salary, workload) and mental health, with spaces to share the anxieties, challenges and achievements of teachers at school.

Keywords: Burnout. “Maslach Burnout Inventory”. School teachers.

\section{INTRODUÇÃO}

A saúde mental é uma prioridade para a saúde pública, devido a sua importância nos níveis individual e coletivo. Seu conceito implica três componentes: o bem-estar, as habilidades intrapessoais (para lidar consigo) e interpessoais (para lidar na comunidade); o estado de bem-estar individual consiste na auto percepção de seu potencial, capacidade em lidar com estresse cotidiano, trabalhar de forma efetiva e eficiente e, contribuir para sua comunidade (OMS, 2013).

O prejuízo à saúde mental pode ocorrer devido a diversos fatores, sendo os professores uma das populações mais vulnerável em decorrência das especificidades da profissão. A docência exige um envolvimento emocional e intelectual que resulta em desgaste e, consequentemente, exposição a riscos para a saúde (ALVES, 2017; SAMPAIO; STOBÄUS; BAEZ, 2017; SILVA et al., 2018; SANCHEZ et al., 2019). Soma-se às condições precárias de trabalho (SAMPAIO; STOBÄUS; BAEZ, 2017; SILVA et al., 2018) e ao aumento das obrigações frente às mudanças sociais e culturais, como no gerenciamento de conflitos nas instituições de ensino (SAMPAIO; STOBÄUS; BAEZ, 2017), atividades extraclasse ou ameaças verbais e físicas (SILVA et al., 2018).

Deste modo, os professores têm apresentado, frequentemente, o que se denomina como "mal-estar docente" (SAMPAIO; STOBÄUS; BAEZ, 2017), queixas e problemas de saúde (ALVES, 2017; SAMPAIO; STOBÄUS; BAEZ, 2017; SILVA et al., 2018; SANCHEZ et al., 2019). Esta inadequada saúde mental pode culminar na Síndrome de Burnout, que pode ser definida como um esgotamento, um estresse que acomete profissionais, uma síndrome psicológica resultante da tensão emocional constante consequente do trabalho com pessoas (SILVA et al., 2018).

É mister diferenciar o estresse da Síndrome de Burnout. O estresse desaparece após um período de repouso ou descanso, enquanto a Síndrome de Burnout é um estado crônico. Desta forma a Síndrome de Burnout vai além do estresse, mostrando sinais psicológicos tais como: ceticismo, insensibilidade, despreocupação, desconforto e ansiedade (ANDRADE; CARDOSO, 2012). 
Assim, a Síndrome de Burnout advém de agentes causadores do estresse, rotineiramente, no trabalho e que superam a capacidade do indivíduo em lidar com eles (SILVA et al., 2018).

O termo Burnout origina do verbo inglês to burn out referindo-se ao ato de consumir-se, de queima-se por completo. Caracteriza-se pela exaustão emocional, despersonificação e redução da realização pessoal (ALVES, 2017; SILVA et al., 2018). Na década de 80, as investigações sobre Síndrome de Burnout aumentaram e o conceito passou a ser investigado no Canadá, Inglaterra, França, Alemanha, Israel, Itália, Espanha, Suécia e Polônia (MASLACH, 1993).

Os estudos concluem que a síndrome pode causar problemas à saúde como: gastrite, alterações menstruais, alergia, cefaleia, palpitação, hipertensão arterial, uso abusivo de medicamentos e álcool (ANDRADE; CARDOSO, 2012; ALVES, 2017). Diante de tamanha perda de qualidade de vida (ALVES, 2017), alterações psicológicas e físicas (ALVES, 2017; SAMPAIO; STOBÄUS; BAEZ, 2017; SILVA et al., 2018; SANCHEZ et al., 2019) reconhece-se a necessidade da prevenção primária (para identificar as situações causadoras de estresse no ambiente escolar), secundária (para identificar os sinais de estresse, apresentados pelo trabalhador sem adoecimento presente, e que pode se manifestar em outros lugares, como cefaleia, alergia, taquicardia) e, terciária (quando os sintomas não cessam mesmo após o descanso) (HERNANDEZ et al., 2014).

Ademais, o próprio professor deve estar atento à alteração do seu comportamento em relação à capacidade de atuação e consultar médicos e psicólogos para identificar o seu nível de estresse (MACHADO; BOECHAT; SANTOS, 2015). Quando identificada a Síndrome de Burnout pelos especialistas tem-se algumas técnicas que podem ser utilizadas para redução da ansiedade, tais como: meditação, contato sensorial, biofeedback, hipnose, yoga, musicoterapia, esporte e atividades prazerosas (HERNANDEZ et al., 2014).

Uma pesquisa sobre qualidade de vida e Síndrome de Burnout com professores universitários demonstrou a estreita relação entre estes, já que fatores relacionados ao trabalho interferem na qualidade de vida. Apontou a necessidade de intervenções preventivas e de tratamento tendo em vista os prejuízos decorrentes da síndrome. Suas consequências perpassam o âmbito profissional, pela produtividade, afastamentos, absenteísmo e qualidade do processo educativo, e afetam o nível pessoal expressado pelas disfunções pessoais com graves distúrbios psicológicos e físicos (ALVES; OLIVEIRA; PARO, 2019).

Sabendo-se que há muitos fatores predisponentes ao desenvolvimento da síndrome é preciso considerar fatores que envolvem o ambiente de trabalho, e não somente a aula em si. Exemplifica-se um fator de tensão pelo planejamento de aula ter que estar e ser subordinado às esferas superiores, atendendo a interesses políticos, e limitando a autonomia e o papel do professor. Outros aspectos apontados são a baixa remuneração, inadequação da estrutura das instituições de ensino e a superlotação nas salas de aula. Ainda, a mudança e ampliação do papel de professor que assumiu responsabilidades dos agentes tradicionais de socialização, a exemplo da família (ALVES, 2017; SAMPAIO; STOBÄUS; BAEZ, 2017; SILVA et al., 2018; SANCHEZ et al., 2019). 
A partir da vivência profissional em instituições de ensino observou-se as queixas e mau humor diário de professores, do que decorreu o interesse em analisar as dimensões associadas à Síndrome de Burnout. Destarte, este estudo objetivou analisar as dimensões associadas à Síndrome de Burnout em docentes, de uma escola pública, em um município localizado em Minas Gerais. Espera-se contribuir para a saúde mental dos professores, e consequentemente melhorar o processo ensino-aprendizagem em sala de aula.

\section{MATERIAL E MÉTODOS}

A pesquisa, de caráter quantitativo, foi realizada no local onde ocorreram os fenômenos (VERGARA, 2005), constituindo-se, desta forma, em uma pesquisa de campo. A coleta de dados ocorreu junto aos professores de uma escola pública municipal, em uma cidade de Minas Gerais, após assinatura do Termo de Consentimento. O convite para compor a amostra foi estendido a todos os professores do ensino fundamental da escola, e dos quais 20 aceitaram. A faixa etária dos participantes variou entre 28 a 50 anos de idade, sendo todos professores atuantes no ensino fundamental ( $1^{\circ}$ ao $9^{\circ}$ ano $)$ da escola.

Quadro 1 - Formulário quanto às dimensões Burnout

\begin{tabular}{|l|l|l|l|}
\hline Itens & & Não & Sim \\
\hline 1 & Sinto-me emocionalmente esgotado com meu trabalho. & & \\
\hline 2 & Sinto-me esgotado no final de um dia de trabalho. & & \\
\hline 3 & $\begin{array}{l}\text { Sinto-me cansado quando me levanto pela manhã e preciso encarar } \\
\text { outro dia de trabalho. }\end{array}$ & & \\
\hline 4 & Posso entender com facilidade o que sentem as pessoas. & & \\
\hline 5 & Creio que trato algumas pessoas como se fossem objetos. & & \\
\hline 6 & Trabalhar com pessoas o dia todo me exige um grande esforço. & & \\
\hline 7 & Lido eficazmente com o problema das pessoas. & & \\
\hline 8 & Meu trabalho me deixa exausto. & & \\
\hline 9 & $\begin{array}{l}\text { Sinto que através do meu trabalho influencio positivamente na vida } \\
\text { dos outros. }\end{array}$ & & \\
\hline 10 & Tenho me tornado mais insensível com as pessoas. & & \\
\hline 11 & $\begin{array}{l}\text { Preocupa-me o fato de que este trabalho esteja me endurecendo } \\
\text { emocionalmente. }\end{array}$ & & \\
\hline 12 & Sinto-me com muita vitalidade. & & \\
\hline 13 & Sinto-me frustrado com meu trabalho. & & \\
\hline 14 & Creio que estou trabalhando em demasia. & & \\
\hline 15 & $\begin{array}{l}\text { Não me preocupo realmente com o que ocorre às pessoas a que } \\
\text { atendo. }\end{array}$ & \\
\hline 16 & Trabalhar diretamente com as pessoas me causa estresse. & & \\
\hline 17 & Posso criar facilmente uma atmosfera relaxada para as pessoas. & & \\
\hline 18 & Sinto-me estimulado depois de trabalhar em contato com as pessoas. & & \\
\hline 19 & Tenho conseguido muitas realizações em minha profissão. & & \\
\hline 20 & Sinto-me no limite de minhas possibilidades. & & \\
\hline 21 & Sinto que sei tratar de forma adequada os problemas emocionais no & & \\
\hline 22 & Sinto trabalho. & & \\
\hline
\end{tabular}

Fonte: Maslach Burnout Inventory (2016), adaptado 
Para a coleta de dados foi feito previamente um contato pessoal com a escola e com os professores a fim de explicar o objetivo da pesquisa, a justificativa e metodologia. Em seguida o questionário foi entregue, na sala de professores, não ficando estipulado um tempo limite para responder as questões. O instrumento de coleta de dados foi "Maslach Burnout Inventory" $\mathrm{MBI}$, adaptado a partir do formulário proposto por Maslach e Jackson (1981) (Quadro 1).

A análise dos dados consistiu-se em classificar as respostas segundo cada dimensão que concretiza a Síndrome de Burnout, conforme Maslach e Jackson (1986): desgaste emocional (sentimento de sobrecarga), despersonalização (sentimento negativo em relação ao próximo) e realização pessoal. Cada item do instrumento corresponde a uma das três dimensões da síndrome: Exaustão Emocional (itens: 1, 2, 3, 6, 8, 13, 14, 16 e 20); Despersonalização $(5,10,11,15,22)$; Realização Pessoal no Trabalho $(4,7,9$, $12,17,18,19,21)$.

\section{RESULTADOS E DISCUSSÃO}

Na dimensão "Realização Pessoal no Trabalho" o item com maior número de repostas afirmativas foi o item 9: Sinto que através do meu trabalho influencio positivamente na vida dos outros, com 17 participantes (85\%). $O$ item 4 e o item 19, Posso entender com facilidade o que sentem as pessoas e Tenho conseguido muitas realizações com a minha profissão, respectivamente, foram assinalados positivamente por 12 participantes (60\%). O item 21: Sinto que sei tratar de forma adequada os problemas emocionais no meu trabalho foi marcado por 11 professores (55\%). O item: Posso criar facilmente uma atmosfera relaxada para as pessoas foi escolhido por nove participantes (45\%). Oito professores (40\%) assinalaram o item: Sinto-me com muita vitalidade. Apenas quatro professores (20\%) marcaram o item: Lido eficazmente com os problemas das pessoas.

A dimensão "Exaustão Emocional", fase da Síndrome de Burnout, está relacionada à sensação de sobrecarga. Neste quesito a frase: Sinto-me esgotado no final de um dia de trabalho foi a mais assinalada, correspondendo a 14 afirmativas (70\% dos professores). Em seguida, o item mais assinalado foi: Sinto-me emocionalmente esgotado com meu trabalho, por 12 participantes (60\%). O item 16: Trabalhar diretamente com pessoas me causa estresse foi o terceiro mais apontado, sendo que 11 professores o selecionaram (55\%). Os itens 3, (Sinto-me cansado quando me levanto pela manhã e preciso encarar outro dia de trabalho), 6 (Trabalhar com pessoas o dia todo me exige um grande esforço) e, 20 (Sinto-me no limite das minhas possibilidades) obtiveram a mesma quantidade de respostas afirmativas, 10 participantes (50\%). O item 13: Sintome frustrado com meu trabalho foi apontado por nove professores (45\%). Os itens: Meu trabalho me deixa exausto (8) e Creio que estrou trabalhando em demasia (14) obtiveram afirmação de sete participantes (35\%).

A dimensão "Despersonalização" relaciona-se a sentimentos negativos em relação às pessoas. De forma predominantes, 10 professores $(50 \%)$ concordam com a afirmação: Tenho me tornado mais insensível com as pessoas. Nove professores (45\%) estavam preocupados em estarem se 
tornando mais rígido emocionalmente como consequência ao trabalho (item 11). E seis participantes (30\%) concordaram com a frase Sinto que as pessoas me culpam de algum modo pelos seus problemas; quatro professores (20\%) acreditam que tratam algumas pessoas como se fossem objetos (item 5) e três professores (15\%) dizem não se preocuparem realmente com as pessoas que atendem.

O item mais assinalado em cada dimensão foi: Sinto que através do meu trabalho influencio positivamente na vida dos outros (85\% - Realização Pessoal no Trabalho), Sinto-me esgotado no final de um dia de trabalho (70\% - Exaustão Emocional), Tenho me tornado mais insensível com as pessoas $(50 \%$ Despersonalização).

Ademais, os itens seguintes mais assinalados se encontram nas dimensões Realização Pessoal no Trabalho: Posso entender com facilidade o que sentem as pessoas (60\%), Tenho conseguido muitas realizações com a minha profissão (60\%), e em Exaustão Emocional: Sinto-me emocionalmente esgotado com meu trabalho (60\%).

Percebe-se que quase todos os professores apresentam o sentimento de influenciar positivamente a vida dos alunos (item 9). E, esse sentimento pode estar relacionado a um forte comprometimento com a profissão (ALVES, 2017; SILVA et al., 2018). Os itens 4 (no entendimento do sentimento das pessoas) e 19 (realizações na profissão) complementam o item 9 (sentimento de influenciador) quanto à satisfação pessoal no trabalho.

Porém, nem sempre as condições são favoráveis no exercício da docência: condições precárias de trabalho (SAMPAIO; STOBÄUS; BAEZ, 2017; SILVA et al., 2018), atividades extraclasse, violência física e verbal (SILVA et al., 2018) e, aumento de funções, como no gerenciamento de conflitos nas instituições de ensino (SAMPAIO; STOBÄUS; BAEZ, 2017) acabam por desgastar os professores.

A insatisfação abrange desde a estrutura física da escola, até a falta de autonomia, participação e boa relação na escola (ALVES, 2017; SAMPAIO; STOBÄUS; BAEZ, 2017; SILVA et al., 2018; SANCHEZ et al., 2019). Todos estes fatores somam-se ao desgaste de envolvimento emocional e intelectual, inerente à profissão (ALVES, 2017; SAMPAIO; STOBÄUS; BAEZ, 2017; SILVA et al., 2018; SANCHEZ et al., 2019), e se relacionam com o segundo item mais assinalado pelos professores: Sinto-me esgotado no final de um dia de trabalho, correspondente à dimensão Exaustão Emocional. Apesar desta sensação de esgotamento físico ser esperada, faz-se necessária atenção e cautela, pois é tênue a margem entre o esperado e o patológico.

Este esgotamento não é um cansaço natural após o dia de trabalho, mas uma exaustão que reflete em dor física e afeta diretamente as relações interpessoais e a qualidade de vida do professor em diversos âmbitos, inclusive na relação com os alunos (ALVES, 2017; SANCHEZ et al., 2019). Com certa frequência, os professores têm apresentado queixas e problemas de saúde (ALVES, 2017; SAMPAIO; STOBÄUS; BAEZ, 2017; SILVA et al., 2018; SANCHEZ et al., 2019).

Conclui-se que há uma correlação entre os dois itens mais assinalados (2 e 9) uma vez que há um sentimento de comprometimento dos professores com a profissão, como influenciadores positivos para os alunos, mas que se esgotam 
ao se deparar com os desafios, insatisfação e excesso de demanda no ambiente de trabalho.

Ainda na dimensão de Exaustão Emocional, têm-se os itens 16: Trabalhar diretamente com pessoas me causa estresse (55\% dos professores), seguido do item 3: Sinto-me cansado quando me levanto pela manhã e preciso encarar outro dia de trabalho (50\%), e do item 20: Sinto-me no limite de minhas possibilidades (50\%). Ou seja, a exaustão é manifestada, majoritariamente, no esgotamento, desgaste emocional, seguido de indisposição para atividades rotineiras e convívio com as pessoas

Quanto ao item 16, infere-se que o trabalho direto com pessoas possibilita um envolvimento com situações e problemas dos alunos, que mediante 0 compromisso profissional $e$ os fatores desgastantes desencadeia um mecanismo de autopreservação: Despersonalização.

Quanto à dimensão Despersonalização a resposta predominante foi 0 item 10: Tenho me tornado mais insensível com as pessoas, com 50\% de concordância. E, nove professores (45\%) demonstraram preocupação por estarem se tornando mais rígidos emocionalmente como consequência do trabalho (item 11). Resultado semelhante foi encontrado em uma pesquisa com professores em Niterói (SILVA et al., 2018).

A grande quantidade de professores que se referem à insensibilidade com as pessoas é preocupante, pois os alunos necessitam de atenção, e da relação interpessoal positiva entre aluno e professor, além dos demais membros da comunidade escolar

\section{CONCLUSÃO}

Os professores se comprometem fortemente com a profissão, evidenciado na dimensão Realização Pessoal no Trabalho. Porém, se deparam com condições nem sempre favoráveis para o trabalho resultando em Exaustão Emocional. Somado ao convívio e envolvimento diário com alunos, pais, membros da escola e comunidade acabam por exacerbar o desgaste e desenvolver um mecanismo de proteção, a Despersonalização.

Sabe-se que a Síndrome de Burnout pode gerar além de perda de qualidade de vida dos professores, em implicações pedagógicas. Desse modo, faz-se necessário reconhecer e intervir nos agentes causadores do estresse no cotidiano do professor.

Para tal, apesar das limitações deste estudo pela pequena amostra, sugere-se que haja mais pesquisas e esforços para: vivência da prática docente desde o início da licenciatura com problematização das situações geradoras de estresse na escola e, busca por soluções em parceria com a escola, os professores e colegas na graduação e a comunidade; abordar a temática do "mal-estar docente" contextualizando a teoria com a prática docente; melhoria das condições de trabalho (estrutura física, salário, carga horária) e da saúde mental, com espaços para compartilhar angústias, desafios e conquistas dos professores na escola. 


\section{REFERÊNCIAS}

ALVES, P. C. Qualidade de vida e esgotamento profissional do professor universitário. 2017. 139 f. Tese (Doutorado em Ciências da Saúde) - Faculdade de Medicina, Universidade Federal de Uberlândia, Uberlândia, 2017.

ALVES, P. C.; OLIVEIRA, A. F.; PARO, H. B. M. S. Qualidade de vida e burnout entre os docentes: Quanto é importante o campo do conhecimento? PLoS ONE, v. 14, n. 3, e0214217 2019. Disponível em: <https://doi.org/10.1371/journal.pone. 0214217>. Acesso em 23 mar. 2019.

ANDRADE, P. S.; CARDOSO, T. A. O. Prazer e dor na Docência: revisão bibliográfica sobre a Síndrome de Burnout. Saúde Sociedade, v. 21, n. 1, p. 129140, 2012. Disponível em: <https://www.scielo.br/scielo.php?script=sci_abstract \&pid=S0104-12902012000100013\&lng=es\&nrm=iso\&tlng=pt>. Acesso em: 19 jun. 2019.

DIEHL, L.; CARLOTTO, M. S. Conhecimento de professores sobre a Síndrome de Burnout: processo, fatores de risco e consequências. Psicologia em Estudo, v. $19, \quad$ n. $4, \quad$ p. 741-752, 2014. Disponível em: $<$ https://www.scielo.br/scielo.php?pid=S1413-73722014000400741\&script=sci _abstract\&tlng=pt>. Acesso em: 19 jun. 2019.

HERNÁNDEZ, E. G. et al. Prevenção e intervenção na síndrome de burnout. Como prevenir (ou remediar) o processo de burnout. In: PEREIRA, A. M. B. (Org). Burnout: quando o trabalho ameaça o bem-estar do trabalhador. $4^{\mathrm{a}}$ ed. São Paulo: Casa do Psicólogo, 2014, p. 227-272.

KOGA, G. K. C. et al. Fatores associados a piores níveis na escala de Burnout em professores da educação básica. Cadernos Saúde Coletiva, v. 23, n. 3, p. 268-275, 2015. Disponível em: <https://www.scielo.br/scielo.php?script=sci_ abstract\&pid=S1414-462X2015000300268\&lng=en\&nrm=iso\&tlng=pt>. Acesso em: 19 jun. 2019.

MACHADO, V. R.; BOECHAT, I. T.; SANTOS, M. F. R. Síndrome de Burnout: uma reflexão sobre a saúde mental do educador. Revista Transformar, v. 7, p. 257-272, 2015. Disponível em: <http://www.fsj.edu.br/transformar/index.php/ transformar/article/view/44/41>. Acesso em: 20 out. 2018.

MASLACH, C. Burnout: A multidimensional perspective. In: SCHAUFELI, W. B.; MASLACH, C; MAREK, T. (Eds.) Esgotamento profissional: desenvolvimentos recentes em teoria e pesquisa. Londres: Taylor e Francis, 1993, p. 19-32.

MASLACH, C.; JACKSON, S. E. The measurement of experienced burnout. Journal of Occupational Behaviour, v. 2, n. 2, p. 99-113, 1981. Disponível em: $<$ https://onlinelibrary.wiley.com/doi/epdf/10.1002/job.4030020205>. Acesso em: 19 jun. 2019. 
MASLACH, C.; JACKSON, S. E.; LEITER, M. P. Maslach Burnout Inventory. Palo Alto: Consulting Psychologist Press, 1986, p. 191-218. Disponível em: $<$ https://www.researchgate.net/profile/Christina_Maslach/publication/277816643 _The_Maslach_Burnout_Inventory_Manual/links/5574dbd708aeb6d8c01946d7. pdf>. Acesso em: 19 jun. 2019.

ORGANIZAÇÃO MUNDIAL DE SAÚDE (OMS). Plan de Acción Sobre Salud Mental 2013-2020. Suíça: Genebra. 2013. Disponível em: <http://apps.who.int/iris/bitstream/handle/10665/97488/9789243506029_spa.pdf ?sequence=1>. Acesso em: 19 jun. 2019.

SAMPAIO, A. A.; STOBÄUS, C. D.; BAEZ, M. A. C. Vivências de mal-estar na transição da licenciatura à docência. Movimento - Revista de Educação Física da UFRGS, v. 23, n. 3, p. 975-988, 2017. Disponível em: <https://seer.ufrgs.br/Movimento/article/view/65257>. Acesso em: 19 jun. 2019.

SANCHEZ, H. M. et al. Impacto da saúde na qualidade de vida e trabalho de docentes universitários de diferentes áreas de conhecimento. Ciência \& Saúde Coletiva, v. 24, n. 11, p. 4111-4122, 2019. Disponível em: <http://dx.doi.org/10.1590/1413-812320182411.28712017>. Acesso em: 25 jul. 2020.

SILVA, J. L. L. et al. Prevalência da síndrome de Burnout entre professores da Escola Estadual em Niterói, Brasil. Enfermería Actual en Costa Rica, n. 34, p. 14-25, 2018. Disponível em: <https://pesquisa.bvsalud.org/portal/resource/pt/ biblio-891490>. Acesso em: 19 jun. 2019.

VERGARA, S. C. Métodos de pesquisa em administração. São Paulo: Atlas, 2005. 